\title{
Caracterização da saúde de crianças atendidas em creches e prevenção dos distúrbios de comunicação
}

\author{
Health profile of children cared for in nurseries and the prevention of communication \\ disturbs
}

\author{
Mariangela Lopes Bitar*, Maria do Rosario D.O. Latorre**, Andréa Viude***, Lúcia N. Takahashi***, \\ Viviane P.P. Silva
}

\begin{abstract}
BITAR, M.L. et al. Caracterização da saúde de crianças atendidas em creches e prevenção dos distúrbios de comunicação. Rev. Saúde Pública, 28:46-58, 1994. Com o objetivo de caracterizar a saúde da população atendida pelo Programa Creche, desenvolvido em três unidades conveniadas com a Prefeitura do Município de São Paulo (Brasil), foi feito um inquérito junto a essa população. Foram aplicados 133 questionários com perguntas abertas e fechadas relativas à identificação e antecedentes pessoais, desenvolvimento e saúde. Os resultados mostraram que crianças residentes em moradias desfavoráveis, com umidade e grande número de pessoas na casa apresentaram maior número de infecçōes respiratórias e de otite. A maioria das crianças foi aleitada naturalmente, passando para amamentação artificial com dois meses. Os alimentos salgados e de texturas variadas foram introduzidos na idade adequada e bem aceitos. Atraso de linguagem é referido predominantemente dos 3 aos 7 anos. Os pais atuam adequadamente em situações de comunicação. Conclui-se que a aplicação sistemática do questionário proposto permitirá não somente obter maior conhecimento das condições de saúde das crianças, favorecendo $o$ atendimento multidisciplinar e integrado da criança, como otimizar condutas preventivas e possibilitar a realização de vigilância de distúrbios da comunicação.
\end{abstract}

Descritores: Desenvolvimento da linguagem. Questionários. Creches. Integrą̧ão docente-assistencial.

\section{Introdução}

O Curso de Fonoaudiologia da Faculdade de Medicina da Universidade de São Paulo desenvolve, desde 1985, o Estágio Supervisionado em Assistência Primária - Programa Creche, em três unidades conveniadas com a Prefeitura Municipal de São Paulo (Bitar ${ }^{1}$, 1988).

O Programa abrange as áreas de linguagem e audição e nele participam quatro supervisores, sendo dois docentes contratados, um técnico especializado e um professor convidado e, ainda, os alunos do terceiro ano do Curso de Fonoaudiologia.

O objetivo do Programa é promover o desenvolvimento da criança nas áreas alvo e atuar para a

* Departamento de Clínica Médica da Faculdade de Medicina da Universidade de São Paulo - São Paulo, SP - Brasil

** Departamento de Epidemiologia da Faculdade de Saúde Pública da Universidade de São Paulo - São Paulo, SP . Brasil

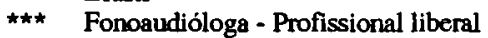

Separatas/Reprints: M.L. Bitar - Rua Cipotania, 51 - 05508-900 São Paulo, SP - Brasil

Edição subvencionada pela FAPESP. Processo 94/0500-0. prevenção de distúrbios da comunicação, cuidando da proteção específica. Para tanto, as atividades envolvem a atuação direta com a criança, que se constituem em: triagem (levantamento do perfil de cada grupo-classe) e estimulação da audição, linguagem, fala, sistema sensório motor oral e funções alimentares. Com relação aos responsáveis pela educação e saúde - pais e profissionais de creche - Programa visa à formação de agentes multiplicadores através de treinamentos, reciclagens e orientações. Inclui-se, também, entre as atividades, o encaminhamento das crianças para especialistas: fonoaudiólogos, odontólogos, otorrinolaringologistas e outros que se mostrem necessários.

O Programa Creche não se volta apenas para a criança. $O$ trabalho de educação visa à comunidade, lugar onde ocorrem as mudanças decorrentes da aplicação das atividades de promoção do desenvolvimento da linguagem e da audição.

O ensino do aluno encontra nesse Programa desenvolvido junto à comunidade, um espaço para aquisição de conhecimento e reflexão crítica sobre a realidade experenciada. A atuação em um programa de assistência primária permite, ao futuro pro- 
fissional, uma formação mais abrangente, uma vez que, historicamente, o fonoaudiólogo dedicava-se essencialmente ao atendimento nos níveis da assistência terciária e secundária.

Além de se voltar para objetivos de ensino e assistência, o Programa Creche está direcionado também para a realização de pesquisa.

Considerando que ao se visar a linguagem é necessário olhar para o individuo de maneira globalizada, e baseado no fato de que o Programa apresenta ações voltadas para grupos e seus contextos, é importante que se conheça, mais profundamente, as condições de saúde da população atendida. Porém não se encontrou na literatura brasileira, nenhum inquérito voltado para a área de fonoaudiologia, específico para avaliar essas condições do indivíduo.

Nesse sentido, foi elaborado um instrumento onde se procurou selecionar itens que abordassem aspectos inter-relacionados com o desenvolvimento da linguagem e que, também, fornecessem dados que auxiliassem na deteç̧ão precoce de eventuais distúrbios (atraso de linguagem, distúrbio articulatório, disfluência, alterações mio funcionais orais, distúrbio de audição, distúrbios na fonação), como objetivo de caracterizar a saúde das crianças que freqüentam os equipamentos assistidos pelo Programa Creche. A elaboração desse instrumento baseou-se na experiência de Marcondes ${ }^{4}$ e Grünspun $^{2}$.

Marcondes ${ }^{4}$ (1985) sugere um roteiro de anamnese que apresenta os seguintes itens: queixa e duração, história pregressa da moléstia atual, interrogatório sobre os diversos sistemas do corpo humano, antecedentes familiares e pessoais, condições habituais da vida da criança (condições alimentares, condições de funcionamento intestinal, salubridade da casa, em especial do quarto da criança e freqüência de resfriados e condições de resfriados e condições neuropsiquicas).

Por sua vez, Grünspun ${ }^{2}$ (1980) em sua proposta de "Roteiro de Anamnese em Psiquiatria Infantil $^{1 "}$, investiga os seguintes aspectos: identificação, queixa ou motivo da consulta, antecedentes pessoais (concepção, gestação, condições de nascimento, desenvolvimento psicomotor, manipulações e hábitos, sociabilidade, sexualidade, escolaridade e doenças), antecedentes familiares, descrição de um dia da criança e anamnese familiar.
O questionário elaborado para o Programa Creche, com base nos citados autores, foi testado em três creches com vistas a verificar a adequação e exeqüibilidade das questões nele contidas, bem como validar as instruções do Manual de Aplicação que o acompanha, além de avaliar o treinamento das estagiárias que estão envolvidas no Programa.

O presente trabalho tem, pois, o objetivo de apresentar os resultados da aplicação do questionário e indicar as alterações propostas para sua reformulação.

\section{Material e Método}

\section{População de Estudo}

Os três equipamentos acompanhados pelo Programa Creche foram:

-Creche Jardim Julieta

-Creche Santíssima Trindade

- Creche Maria de Nazaré

Localizadas na região do Butantã, na área circunscrita ao Centro de Saúde Escola Samuel B. Pessoa, essas creches atendem à população de baixa renda. As creches Jardim Julieta e Maria de Nazaré recebem crianças na faixa etária de 0 a 6 anos, enquanto que a Santíssima Trindade, a partir de 3 anos. As crianças permanecem em período integral nas creches que oferecem cinco refeições diariamente. Cada uma das três creches conta, no seu quadro de funcionários, com uma administradora, uma professora, uma atendente de enfermagem, pajens, cozinheira, lactarista e funcionários de limpeza.

A população de estudo constituiu-se de 133 crianças, sendo todas as que compunham os grupos de Berçário e Mini-grupo (78 crianças na faixa etária de 2 meses a 2 anos e 11 meses) e uma amostra de $20 \%$ das crianças dos grupos Maternal I, Maternal II, Jardim e Pré (55 crianças entre 3 anos completos e 7 anos e 2 meses).

Decidiu-se trabalhar com todas as crianças da primeira faixa etária ( 2 meses a 2 anos e 11 meses), pois havia maior interesse na obtenção de dados complementares sobre o desenvolvimento dos bebês, uma vez que, de acordo com a estratégia adotada pelo Programa Creche, os mesmos são acompanhados individualmente de forma continuada. 
Quanto ao outro grupo, optou-se por sortear uma amostra aleatória, sistemática de $20 \%$ das crianças que o compunham, pois a pesquisa iniciouse em setembro de 1990 e não havia tempo hábil para se fazer o inquérito em todo o grupo até o fim do ano letivo. Para o sorteio foi utilizada a relação de crianças de cada grupo em ordem alfabética.

\section{Instrumento de Medida}

Foi elaborado questionário com perguntas abertas e fechadas englobando aspectos relativos à identificação pessoal, antecedentes pessoais, desenvolvimento e saúde.

\section{Identificação Pessoal}

Foram considerados: local e data de nascimento, idade da criança e dos pais, altura e peso atuais da criança e ao nascer, posição na constelação familiar, condições de moradia quanto ao tipo de construção (alvenaria: construção de tijolos ou blocos de cimento ou barraco: construção de madeira), presença de umidade e ainda, com quantas pessoas mora, onde e com quantos dorme.

\section{Antecedentes Pessoais}

Deste item constam aspectos relativos às condições de gestação (realização ou não de pré-natal, local e período do mesmo, ocorrência de acidentes e/ou doenças da mãe, uso de medicações, realização de exames e tempo gestacional) e nascimento (tipo de parto, sua duração, tipo de anestesia, local, reações, intercorrências, Apgar e fator Rh).

III. Desenvolvimento

Aspectos relativos ao sono, à alimentação, à linguagem, à sociabilidade e hábitos orais.

\section{Saúde}

Pesquisou-se informações a respeito da criança e em relação à família. No que tange à criança, verificou-se a carteira de vacinações e doenças hereditárias e outras como: varicela, caxumba, sarampo, rubéola, escarlatina e pneumonia e verificou-se sobre a ocorrência de amigdalite e otite. Quando se tratava de intervenções cirúrgicas foram investigados o motivo, local, período e evolução e foi verificado o uso de drogas ototóxicas.

Com respeito à saúde dos familiares inqüiriuse sobre a ocorrência de sindromes, deficiência mental, deficiência auditiva, fissura lábio-palatina, distúrbios de comunicação e outras.
Para efeito do presente estudo, optou-se por trabalhar com as seguintes variáveis, por considerá-las mais importantes para caracterizar a saúde das crianças*:

- números de pessoas que moram na residência;

- caracterização da moradia (se barraco ou alvenaria e se o ambiente é úmido ou seco);

- doenças da criança referidas pela mãe ou outro familiar;

- desenvolvimento da linguagem da criança;

- alimentação: idades de término da amamentação natural, de início e término da amamentação artificial e introdução de novas texturas na dieta da criança;

- relacionamento dos pais com a criança no que se refere ao estímulo em relação ao desenvolvimento de linguagem;

- gestação e parto: tempo de gestação, realização de pré-natal e tipo de parto;

- doenças referidas na família.

\section{Procedimentos}

O questionário foi aplicado de setembro a novembro de 1991, pelas doze estagiárias envolvidas no Programa Creche, que solicitavam à atendente de enfermagem ou diretora da instituição que convocassem os pais das crianças, dando-se preferência a fazer a entrevista com a mãe.

No momento da convocação era pedido aos pais que trouxessem, no dia da entrevista, as carteiras de vacinação e da maternidade, uma vez que, com base nelas, eram preenchidos os itens relativos à vacinação, ao índice Apgar e fator $R h$.

Quando o familiar faltava à entrevista era feita nova convocação procurando-se adequar o horário da entrevista ao do respondente.

$\mathrm{O}$ questionário foi aplicado, individualmente, na própria creche, em salas que permitissem preservar o par (entrevistado/estagiária) de interferências externas que pudessem afetar aquela situação.

Caso a pessoa entrevistada tivesse mais de um filho na creche, a mesma estagiária aplicava os questionários referentes a todas as crianças.

O conjunto dos dados levantados foi apresentado no IV Congresso Brasileiro de Fonoaudiologia, Santa Maria, 1991, por Viude e col. ${ }^{6}$ 
Todas as estagiárias foram treinadas em uma sessão que antecedeu às entrevistas. Dúvidas referentes à aplicação foram esclarecidas durante o período de supervisão do estágio com a finalidade de garantir a homogeneidade na realização do levantamento.

\section{Resultados e Discussão}

O presente estudo permitiu conhecer algumas condiçōes socioeconômicas e de saúde da população atendida pelo Programa Creche, favorecendo o direcionamento das ações dos profissionais envolvidos na proteção específica da linguagem e audição, bem como avaliar o instrumento de coleta dessas informações.

Ao se caracterizar o ambiente em que a criança mora, observou-se que na Creche Maria de Nazaré as crianças moravam, em média, com mais 4 pessoas, o mesmo ocorrendo na Creche Santíssima Trindade. Já na Creche Jardim Julieta, a média foi de 4,8 pessoas. Tanto na Maria de Nazaré quanto na Santíssima Trindade o número máximo de pessoas mais baixo e condições insalubres para os moradores. As condições insalubres podem representar moradias com pouca ventilação favorecendo o aparecimento de infeç̧ões das vias aéreas e otites. No entanto, o instrumento aplicado não mediu as variáveis número de cômodos na residência e presença de ventilação, restringindo a caracterização da moradia às variáveis presença de umidade e tipo de material de construção. Informações mais precisas passaram a ser levantadas com a inclusão de perguntas relativas ao número de cômodos e em que cômodo da casa a criança dorme.

Nas três creches pesquisadas pôde-se verificar que $69,2 \%$ de crianças morava em casa de alvenaria, enquanto que $30,8 \%$ em barraco. De todas as moradias pesquisadas, $37,6 \%$ é úmida e $62,4 \%$ é seca.

A Creche Jardim Julieta se diferencia das demais apresentando uma maior proporção $(41,7 \%)$ de moradias úmidas, embora seja maior a proporção de habitações de alvenaria. Tal fato também propicia o aparecimento de infecções respiratórias.

Entre as doenças referidas verificou-se que,

Tabela 1. Número e percentagem de crianças matriculadas nas creches Maria de Nazaré (MN), Jardim Julieta (JJ) e Santissima Trindade (ST), segundo a idade (em meses) de término da amamentação natural. São Paulo, setembro a novembro de 1990.

\begin{tabular}{|c|c|c|c|c|c|c|c|c|}
\hline \multirow{3}{*}{$\begin{array}{c}\text { Idade } \\
\text { (meses) }\end{array}$} & \multicolumn{6}{|c|}{ Creche } & \multirow{2}{*}{\multicolumn{2}{|c|}{ Total }} \\
\hline & \multicolumn{2}{|c|}{$M N$} & \multicolumn{2}{|c|}{$\mathrm{JJ}$} & \multicolumn{2}{|c|}{ ST } & & \\
\hline & $\mathrm{N}^{\circ}$ & $\%$ & $\mathrm{~N}^{*+*+\infty}$ & $\%$ & $\mathrm{~N}^{2}$ & $\%$ & $N^{2}$ & $\%{ }^{*}$ \\
\hline $0-2$ & 16 & 45,7 & 24 & 40,0 & 7 & 35,0 & 47 & 40,9 \\
\hline $3-5$ & 4 & 11,4 & 17 & 28,4 & 4 & 20,0 & 25 & 21,7 \\
\hline $6-8$ & 4 & 11,4 & 12 & 20,0 & 5 & 25,0 & 21 & 18,3 \\
\hline $9-12$ & 3 & 8,6 & 3 & 5,0 & 2 & 10,0 & 8 & 7.0 \\
\hline $13-24$ & 5 & 14,3 & 2 & 3,3 & 2 & 10,0 & 9 & 7,8 \\
\hline 25 e mais & 3 & 8,6 & 2 & 3,3 & - & - & 5 & 4,3 \\
\hline s/informac & 2 & 5,4 & 3 & 4,8 & - & - & 5 & 4,2 \\
\hline Total & 37 & 100,0 & 63 & 100,0 & 20 & 100,0 & 120 & 100,0 \\
\hline
\end{tabular}

\footnotetext{
- Excluidas 4 crianças que utilizaram somente amamentação artificial

- Percentagem calculada com exclusão dos sem informação

*.* Excluidas 9 crianças que utilizaram somente amamentação artificial
}

na residência foi de 9 . Este número elevou-se para $11,13,15$ e até 18 pessoas para as crianças que freqüentavam a Creche Jardim Julieta.

Um número maior de pessoas morando na mesma residência pode refletir um poder aquisitivo considerando as três creches conjuntamente, a otite ocorreu com maior freqüência $(51,9 \%)$ seguida pela pneumonia $(41,4 \%)$, varicela $(34,6 \%)$ e amigdalite $(27,8 \%)$. Outras doenças com menor freqüência foram: parotidite, rubéola, sarampo e hepatite. 
Tabela 2. Número e percentagem de crianças matriculadas nas Creches Maria de Nazaré (MN), Jardim Julieta (JJ) e Santíssima Trindade (ST), segundo a Idade (em meses) do início da amamentação artificial. Sảo Paulo, setembro a novembro de 1990.

\begin{tabular}{|c|c|c|c|c|c|c|c|c|}
\hline \multirow{3}{*}{ Idade } & \multicolumn{6}{|c|}{ Creche } & \multirow{2}{*}{\multicolumn{2}{|c|}{ Total }} \\
\hline & \multicolumn{2}{|c|}{ MN } & \multicolumn{2}{|c|}{ JJ } & \multicolumn{2}{|c|}{ ST } & & \\
\hline & №* & $\%$ & $N^{N * * * *}$ & $\%$ & $N^{2 * * * * *}$ & $\%$ & № & $\%$ \\
\hline $0-2$ & 24 & 64,9 & 34 & 49,3 & 10 & 52,0 & 68 & 54,4 \\
\hline $3-5$ & 5 & 13,5 & 21 & 30,4 & 4 & 21.1 & 30 & 24,0 \\
\hline $6-8$ & 5 & 13,5 & 10 & 14,5 & 4 & 21,1 & 19 & 15,2 \\
\hline $9-12$ & 3 & 8,1 & 2 & 2,9 & - & - & 5 & 4,0 \\
\hline $13-24$ & - & - & 2 & 2,9 & 1 & 5,3 & 3 & 2,4 \\
\hline s/informac & 2 & 5,1 & 1 & 1,4 & - & - & 3 & 2,3 \\
\hline Total & 39 & 100,0 & 70 & 100,0 & 19 & 100,0 & 128 & 100,0 \\
\hline
\end{tabular}

- Excluídas 2 crianças que não aceitaram a amamentação artificial

- Percentagem calculada com exclusão dos sem informação

*** Excluídas 2 crianças que não aceitaram a amamentação artificial

**** Excluída 1 criança que não aceitou a amamentação artificial

$\mathrm{Na}$ Creche Jardim Julieta, que apresentou maior concentração de moradores por residência e maior proporção de moradias úmidas, metade das crianças já havia tido pneumonia contra $36 \%$ da Creche Maria de Nazaré e 20\% da Creche Santissima Trindade. Infeç̧ões respiratórias repetidas podem comprometer a função respiratória nasal, provocando alterações dos órgãos fono-articulatórios e, conseqüentemente da fala.

Hubig $^{3}$ (1989) e Souza ${ }^{5}$ (1992), em estudos de creches em São Paulo e no Rio Grande do Sul, respectivamente, encontraram situação semelhante à observada no presente estudo. $\mathrm{O}$ alto índice de ocorrência de otite aponta para a necessidade de medidas preventivas e curativas eficazes, uma vez que a presença constante dessa doença afeta não só a saúde geral da criança, como também, a audição, o desenvolvimento de linguagem e a atenção auditiva.

Em relação à gestação observou-se que a maioria $(88,2 \%)$ das mães das três creches fez pré-natal. Esse percentual pode ser justificado pelo fato de o Centro de Saúde Samuel B. Pessoa e Hospital Universitário - USP estarem situados na mesma região dos equipamentos.

$O$ item gestação, com perguntas referentes ao planejamento familiar e à época em que o pré-natal teve início, foi incluído, no questionário reformulado, pois sentiu-se necessidade de coletar outros elementos para melhor entendimento da relação mãe-criança.
A maioria das crianças $(91,4 \%)$ nasceu de gestação a termo e apenas $0,8 \%$ pós-termo. $O$ tipo de parto que mais se destacou foi o normal $(62,4 \%)$, seguido pela cesárea $(33,1 \%)$ e fórceps $(4,5 \%)$.

Verifica-se na Tabela 1 que entre as 115 crianças que receberam aleitamento natural (exclusão de 18 crianças da amostra total, sendo 13 por terem recebido somente amamentação artificial e 5 por falta de informação no questionário), cerca da metade $(40,9 \%)$ deixou de mamar até o segundo mês de vida, época que pode coincidir com a entrada da criança na creche e/ou com a volta da mãe ao trabalho. Nesse sentido, observa-se na Tabela 2 que das 125 crianças amamentadas artificialmente (exclusão de 5 crianças que não aceitaram amamentação artificial e 3 que não informaram a idade), 68 $(54,4 \%)$ já haviam sido introduzidas nesse tipo de aleitamento aos dois meses de idade.

Acredita-se que esse percentual elevado poderia ser diminuido se houvesse uma preocupação com a manutenção do aleitamento materno. Medidas como incentivo à mãe para ir até a creche amamentar seu filho ao longo do periodo ou até mesmo a criação de um banco de leite fornecido pela própria mãe poderiam ser adotadas garantindo, assim, maior imunidade para os bebês e, conseqüentemente, melhores condições de saúde.

Em relação às 125 crianças que receberam a amamentação artificial, $36,8 \%$ já haviam sido desmamadas e o restante mantinha o aleitamento artificial até o momento da investigação. $O$ desmame 
artificial teve inicio a partir do nono mês como pode-se observar na Tabela 3 . Salienta-se que durante a permanência do bebê no berçário a dieta ainda prescreve o oferecimento de leite, que é dado em mamadeira. O questionário reformulado deverá estender-se às educadoras responsáveis pela criança as perguntas formuladas à mãe, pois sentiu-se a necessidade de levantar informações que permitissem o acompanhamento da amamentação artificial e dieta da criança na própria creche.

Os dados da Tabela 4 mostram que as diferentes consistências, sopa fina, sopa grossa e sólidos, foram introduzidas, em casa, na época esperada para todas as crianças, segundo o relato dos informantes. Isso provavelmente decorre da influência positiva da creche, local onde é respeitada a época de introdução e variação de qualidade dos alimentos oferecidos.

A maioria das crianças $(85,7 \%)$ aceitou bem a introdução de novas texturas alimentares e $79,7 \%$ a dieta salgada. Isso reforça a provável ação positiva da creche, pois a introdução de novas texturas nas idades adequadas propicia condições favoráveis para o desenvolvimento do sistema sensório motor oral e da fala, conseqüentemente, prevenindo distúrbios nessas áreas.

Em relação aos dados fornecidos pelos informantes quanto ao desenvolvimento de linguagem, observa-se, na Tabela 5 , que $76,9 \%$ das crianças da Creche Maria de Nazaré apresentou desenvolvimento normal de linguagem, enquanto que na Creche Jardim Julieta o percentual foi de $56,9 \%$ e na

Tabela 3. Número e percentagem de crianças matriculadas nas creches Maria de Nazaré (MN), Jardim Julieta (JJ) e Santíssima Trindade (ST), segundo a idade (em meses) do término da amamentação artificial. São Paulo, setembro a novembro de 1990.

\begin{tabular}{|c|c|c|c|c|c|c|c|c|}
\hline \multirow{3}{*}{$\begin{array}{c}\text { Idade } \\
\text { (em meses) }\end{array}$} & \multicolumn{6}{|c|}{ Creche } & \multirow{3}{*}{$\begin{array}{c}\text { Total } \\
\text { № } \\
\end{array}$} & \multirow[t]{2}{*}{+} \\
\hline & \multicolumn{2}{|c|}{$M N$} & \multicolumn{2}{|c|}{ JJ } & \multicolumn{2}{|c|}{ ST } & & \\
\hline & №* & $\% "$ & $\mathrm{~N}^{2 * \star \star *}$ & $\% "$ & №***** & $\% "$ & & $\% "$ \\
\hline $0-2$ & - & - & 1 & 5,0 & - & - & 1 & 2,2 \\
\hline $3-8$ & - & - & - & - & - & - & - & - \\
\hline $9-12$ & 4 & 25,0 & - & - & 4 & 40,0 & 8 & 17,4 \\
\hline $13-24$ & 10 & 62,5 & 9 & 45,0 & 3 & 30,0 & 22 & 47,8 \\
\hline 25 e mais & 2 & 12,5 & 10 & 50,0 & 3 & 30,0 & 15 & 32,6 \\
\hline s/informac & 2 & 11,1 & 1 & 4,8 & 1 & 9,1 & 4 & 8,0 \\
\hline Total & 18 & 100,0 & 21 & 100,0 & 11 & 100,0 & 50 & 100,0 \\
\hline
\end{tabular}

* Excluídas 2 crianças que não aceitaram a amamentação artificial e 21 que mantêm esse tipo de dieta * Percentagem calculada com exclusão dos sem informação

*** Excluídas 2 crianças que não aceitaram amamentação artificial e 49 que mantêm esse tipo de dieta **** Excluida uma criança que não aceitou a amamentaçăo artificial e 8 que mantêm esse tipo de dieta

Tabela 4. Número e percentagem de crianças matriculadas nas creches Maria de Nazaré (MN), Jardim Julieta (JJ), Santissima Trindade (ST) que tiveram a introdução de novas texturas na época adequada, segundo a consistência da dieta. São Paulo, setembro a novembro de 1990 .

\begin{tabular}{|c|c|c|c|c|c|c|}
\hline \multirow{3}{*}{ Creche } & \multicolumn{6}{|c|}{ Consistência da dieta } \\
\hline & \multicolumn{2}{|c|}{ Sopa fina } & \multicolumn{2}{|c|}{ Sopa grossa } & \multicolumn{2}{|c|}{ Sólidos } \\
\hline & NN & $\%^{*}$ & № & $\%^{*}$ & $\mathrm{~N}^{\mathrm{S}}$ & $\%$ \\
\hline$M N$ & 24 & 60,0 & 25 & 69,4 & 33 & 84,6 \\
\hline JJ & 48 & 71,6 & 42 & 71,2 & 46 & 78,0 \\
\hline ST & 11 & 64,7 & 11 & 68,8 & 16 & 84,2 \\
\hline Total & 83 & 66,9 & 78 & 70,3 & 95 & 81,2 \\
\hline
\end{tabular}

\footnotetext{
* Percentagem calculada com a exclusão dos ignorados
} 
Tabela 5. Número e percentagem de crianças matriculadas nas creches Maria de Nazaré (MN), Jardim, Julieta (JJ) e Santissima Trindade (ST), segundo idade e o desenvolvimento de linguagem da criança referido pela mãe ou familiar. São Paulo, setembro a novembro de 1990.

\begin{tabular}{|c|c|c|c|c|c|c|c|c|c|}
\hline \multirow[t]{3}{*}{ Creche } & \multirow[t]{3}{*}{ Idade } & \multicolumn{6}{|c|}{ Desenvolvimento } & \multicolumn{2}{|c|}{ Total } \\
\hline & & \multicolumn{2}{|c|}{ Normal } & \multicolumn{2}{|c|}{ Com atraso } & \multicolumn{2}{|c|}{ S/informação } & \multirow[b]{2}{*}{$\mathrm{N}^{2}$} & \multirow[b]{2}{*}{$\%$} \\
\hline & & $\mathrm{N}^{2}$ & $\%{ }^{*}$ & Ne & $\%^{* *}$ & № & $\%$ & & \\
\hline \multirow{3}{*}{ MN } & $2 m--2 a$ & 20 & 83,3 & 4 & 16,7 & 1 & 4 & 25 & 100,0 \\
\hline & $3 a--7 a$ & 10 & 66,7 & 5 & 33,3 & -- & .. & 15 & 100,0 \\
\hline & Total & 30 & 76,9 & 9 & 23,1 & 1 & 2,5 & 40 & 100,0 \\
\hline \multirow{3}{*}{$\mathrm{JJ}$} & $2 m--2 a$ & 26 & 68,4 & 12 & 31,6 & 10 & 20,8 & 48 & 100,0 \\
\hline & $3 a--7 a$ & 7 & 35,0 & 13 & 65,0 & -- & -- & 20 & 100,0 \\
\hline & Total & 33 & 56,9 & 25 & 43,1 & 10 & 14,7 & 68 & 100,0 \\
\hline \multirow[t]{2}{*}{ ST } & $3 a--7 a$ & 9 & 45,0 & 11 & 55,0 & -- & .. & 20 & 100,0 \\
\hline & $2 m--2 a$ & 55 & 77,5 & 16 & 22,5 & 11 & 13,4 & 82 & 100,0 \\
\hline \multirow[t]{2}{*}{ Total } & $3 a-3 a$ & 17 & 37,0 & 29 & 63,0 & -- & -- & 46 & 100,0 \\
\hline & Total & 72 & 61,5 & 45 & 38,5 & 11 & 8,6 & 128 & 100,0 \\
\hline
\end{tabular}

* Excluidas as crianças que ainda não falavam

** Percentagem calculada com a exclusão dos ignorados

Tabela 6. Número* e percentagem de crianças matriculadas nas creches Maria de Nazaré (MN), Jardim Julieta (JJ) e Santíssima Trindade (ST), segundo relacionamento pais-criança, no que se refere a situações de comunicação.São Paulo, setembro a novembro de 1990.

\begin{tabular}{|c|c|c|c|c|c|c|c|c|}
\hline \multirow{3}{*}{ Creche } & \multicolumn{8}{|c|}{ Relação pais-criança } \\
\hline & \multicolumn{2}{|c|}{ Conversam } & \multicolumn{2}{|c|}{ Estimulam } & \multicolumn{2}{|c|}{ Corrigem } & \multicolumn{2}{|c|}{ Sem atençäo } \\
\hline & $\mathrm{N}^{2}$ & $\%$ & $N^{2}$ & $\%$ & $\mathrm{~N}^{2}$ & $\%$ & Ne & $\%$ \\
\hline$M N$ & 34 & 82,9 & 24 & 58,5 & 13 & 31,7 & 6 & 14,6 \\
\hline JЈ & 70 & 100,0 & 59 & 81,9 & 22 & 31,6 & 1 & 1,4 \\
\hline ST & 19 & 95,0 & 13 & 65,0 & 11 & 55,0 & 2 & 10,0 \\
\hline Total & 123 & 94,6 & 96 & 72,2 & 46 & 34,6 & 9 & 6,8 \\
\hline
\end{tabular}

- Percentagem calculada com exclusão dos sem informação

Creche Santíssima Trindade foi de $45,0 \%$.

Encontrou-se atraso no desenvolvimento de linguagem na Creche Maria de Nazaré em 16,7\% das crianças na faixa etária de 2 meses a 2 anos, passando para $33,3 \%$ na faixa etária de 3 a 7 anos. Já na Creche Jardim Julieta, os percentuais foram de $31,6 \%$ e $65,0 \%$ respectivamente, e na Creche Santissima Trindade foi de $55,0 \%$ na faixa etária de 3 a 7 anos. Verifica-se maior número de referências a atraso no desenvolvimento de linguagem na faixa etária de 3 a 7 anos em todas as creches, com predominância na Creche Jardim Julieta.

O elevado número de crianças, cujos pais refe- riam atraso de linguagem, chamou a atenção durante $a$ análise. Nesse momento foi levantada a hipótese de que a expectativa quanto à fala, segundo os pais, pode mudar a cada período do desenvolvimento da criança e esse alto percentual pode estar refletido nesse fato ao invés de representar o efetivo atraso na fala. Uma maneira possivel de analisar os dados obtidos seria investigando o conceito de fala contido em cada referência de idade. Isto porque existe a possibilidade de que a cada período os pais formulem uma idéia sobre o falar, conceituando murmúrio, balbucio, palavras e frases de uma mesma maneira nas diferentes faixas etárias. Nesse

* Questionário reformulado após ter testado. 
sentido, incluiu-se no questionário reformulado questão sobre o conceito de fala para os pais.

Os dados da Tabela 6 indicam que 94,6\% dos pais conversavam com seu filho, $72,2 \%$ estimulavam, $34,6 \%$ corrigiam e apenas $6,8 \%$ não davam atenção. Estes percentuais elevados surgerem revisão na idéia pré-concebida de que os adultos de famílias de baixa renda estabelecem uma relação onde é dada pouca importância à linguagem da criança.

No levantamento das doenças na familia verificou-se que os distúrbios de linguagem oral ocorreram com uma freqüência de $47,5 \%$ sendo que em $26,2 \%$ das famílias encontrou-se gagueira, em $11,5 \%$ retardo de aquisição de linguagem e $9,8 \%$ distúrbio articulatório. A deficiência auditiva ocorreu em $13,8 \%$ das famílias, a deficiência mental em $9,8 \%$ e a fissura labial e/ou palatina em $3,3 \%$. Cabe salientar que essas doenças estavam citadas no questionário. Se o respondente se referia a outra doença, sem relevância para o presente estudo, ela era incluída no item "outras".

Os resultados mostraram que as crianças que viviam em piores condições de moradia quanto ao fator umidade e número de pessoas na casa, o que provavelmente reflete piores condições socioeconômicas, também apresentaram maior número de infecções respiratórias e de otite. Estas infecçōes podem comprometer a respiração nasal e a audição.

A partir desta primeira avaliação do instrumento de medida, as falhas existentes foram corrigidas, com vistas a aumentar a clareza das questões do questionário e complementar a coleta de dados. A nova versão do questionário encontra-se no Anexo 1.

O novo questionário passou a ser aplicado rotineiramente a partir da presente pesquisa junto às familias das creches atendidas pelo Programa Creche que hoje somam sete equipamentos. Sua utilização tem evidenciado a relevância dos dados, uma vez que vem permitindo maior conhecimento das condições de saúde das crianças, bem como a otimização das condutas preventivas.

Os dados também têm sido transferidos para profissionais de outras áreas que trabalham nos equipamentos, favorecendo o atendimento multidisciplinar e integrado da criança.

A aplicação sistemática do instrumento, bem como a análise dos dados, tem permitido a reflexão sobre a atuação fonoaudiológica quanto à possibilidade de realizar a vigilância dos distúrbios da comunicação.

BITAR, M.L. et al. [Health profile of children cared for in nurseries and the prevention of communication disturbs]. Rev. Saúde Pública, 28:46-58, 1994. For the purpose of characterizing the health of the population assisted by the Nursery Program (Programa Creche) at the three units financed by the city authorities of S.Paulo, Brazil, an enquiry was undertaken. Aquestionnaire consisting of both open and closed question concerning personal identification, personal antecedents, development and health was prepared and 133 of them were applied. Results indicated that children whose living conditions were unsatisfactory (humid and overcrowded housing) have presented respiratory infections and otitis in greater numbers. Most of the children were breast-fed at first but started being nursed artificially when two months old. Salty and varied texture foods were introduced at the appropriate ages and well accepted. Language delay is related predominantly to ages 3 to 7 . Parents act properly lin communication situations. It is considered that the systematic use of the questionaire proposed will permit not only better knowledge of the health of the children, benefitting the multidisciplinary attendance and integration of the child, as also the improvement of preventive practices and make the surveillance of difficulties in communication possible.

Keywords: Language development. Questionnaires. Nursery. Teaching care integration.

\section{Referências Bibliográficas}

1. BITAR, M.L. Programa creche da área de atenção primária do Curso de Fonoaudiologia da USP. In: Encontro Nacional de Fonoaudiologia Social e Preventiva, São Paulo, 1988. Anais. São Paulo, CODAC da USP, 1988. p.143-4.

2. GRÜNSPUN, H. Distúrbios psicossomáticos da criança. Rio de Janeiro, Ed. Livraria Atheneu, 1980.

3. HUBIG, D.O.C. Estudo epidemiológico da otite média em população institucionalizada-creche. São Paulo, 1989. [Dissertação de Mestrado - Pontifícia Universidade de São Paulo].

4. MARCONDES, E. Pediatria báscica. São Paulo, Ed. Sarvier, 1985.

5. SOUZA, V.S. Influência da otite média no desenvolvimento da fala. In: I Encontro Internacional da Saúde UFSM, Santa Maria, 1992. Anais. Santa Maria, Imprensa Universitária da UFSM, 1992.

6. VIUDE, A.; TAKAHASHI, L.N.; BITAR, M.L.; SILVA, V.P.P. Caracterização da saúde de crianças de $2 \mathrm{~m}$ a 7 a atendidas pelo Programa Creche - USP. In: Congresso Brasileiro de Fonoaudiologia 5 Santa Maria, 1991. Anais. Santa Maria, Imprensa Universitária da UFSM, 1991.

Recebido para publicação em 22.1.1993 Reapresentado em 14.12.1993 Aprovado para publicą̧ão em 18.1.1994 


\section{ANEXO \\ Modelo de Questionário*}

Programa Creche

CRECHE:

INFORMANTE:

ESTAGIÁRIA:

DATA: PARENTESCO COM A CRLANÇA:

\section{Identificação Pessoal}

1. Nome da criança:

2. Data de nascimento:

3. Com que idade começou a freqüentar a creche:

3.1. Com que idade entrou nesta creche: anos meses.

4. Sexo: ( ) feminino ( ) masculino

5. Em que cidade nasceu? Em que estado? Em que país?

6. Nome da mãe:

Idade: anos. Ocupação:

Freqüentou a escola: ( ) não ( ) sim. Em caso afirmativo (ECA), até que série:

7. Nome do pai:

Idade: anos. Ocupação:

Freqüentou a escola: ( ) não ( ) sim ECA, até que série:

8 Qual a altura da criança: atual: $\mathrm{cm}$. ao nascer: $\mathrm{cm}$.

9. Qual o peso da criança: atual g. ao nascer: g.

10. Caracterização da familia:

10.1. Possui irmãos: ( ) não ( ) sim ECA, quantos?

Se possuir irmãos caracterizar sexo e idade de cada um:

11. Caracterização do ambiente:

11.1. Com quantas pessoas mora?

Caracterizar cada uma segundo sexo, idade e parentesco:

11.2. Quantos cômodos tem a casa?

11.3 Em que cômodo a criança dorme?

11.4. No cômodo, onde a criança dorme?

11.5. Quantas pessoas dormem com a criança no mesmo cômodo?

11.6. Quantas pessoas dormem com a criança no(a) (anotar resposta Q.11.4)

11.7. A casa onde a criança mora é de: ( ) alvenaria ( ) barraco

11.7. A casa onde a criança mora é: ( ) úmida ( ) seca

II. Antecedentes Pessoais

1. Gestação:

1.1. A gestação foi: ( ) planejada ( ) casual

Se casual, qual a reação da mãe?

1.2. Fez pré-natal? ( ) não ( ) sim Quantas consultas?

ECA, qual o local?

a partir de que mês da gestação?

* Questionário reformulado após ser testado. 
1.3. Durante a gestação:

1.3.1. A mãe teve alguma doença? ( ) não ( ) sim

ECA, qual(is)?
( ) rubéola
( ) sifilis
( ) toxoplasmose
( ) diabetes
( ) hipertensão antes dos $4 \mathrm{~m}$ de gestação
( ) hipertensão após os $4 \mathrm{~m}$ de gestação
( ) outras:

1.3.2. A mãe sofreu algum acidente? ( ) não ( ) sim

ECA, qual(is) :

$$
\text { ( ) quedas }
$$

1.3.3. A mãe fez uso do álcool? ( ) não ( ) sim ( ) ocasional

1.3.4. Fez uso do fumo? ( ) não ( ) sim Quantos cigarros por dia?

1.3.5. A mãe passou por algum exame? _ _ ( ) não ( ) sim

ECA, qual(is) :

$$
\text { ( ) raio } \mathrm{X}
$$

1.3.6. A mãe fez uso de medicações? ( ) não ( ) sim

ECA, qual(is) : Para quê?

2. Nascimento:

2.1. Em que local a criança nasceu?
( ) em casa
( ) no hospital
( ) outro:

2.2. Se a criança nasceu no hospital, qual o tipo?

( ) particular ( ) público

E qual o nome do hospital?

2.3. O parto foi: ( ) normal ( ) cesárea ( ) fórceps

2.4. A criança nasceu: ( ) a termo

( ) prematura (de quanto tempo:

( ) pós-termo (de quanto tempo:

3. Primeiras reações da criança:

3.1. A criança chorou ao nascer? ( ) não ( ) $\operatorname{sim}($ ) NS/NQR*

3.2. A criança "ficou" roxa? ( ) não ( ) $\operatorname{sim}($ ) NS/NQR

3.3. A criança precisou de oxigênio? ( ) não ( ) $\operatorname{sim}($ ) NS/NQR

3.4. A criança precisou de internação? ( ) não ( ) $\operatorname{sim}($ ) NS/NQR

ECA, qual o motivo:

( ) ictericia

( ) prematuridade

( ) outros:

4. Desenvolvimento:

4.1. Sono:

4.1.1. Em casa, qual o periodo em que a criança dorme?

4.1.2. Nesse período, qual a duração do sono da criança? 
4.1.4. A criança tem sono agitado? ( ) não ( ) sim

4.1.5. A criança acorda muitas vezes? ( ) não ( ) sim

4.2. Seu filho usa fraldas? ( ) não ( ) sim

ECA, quando?

$\mathrm{ECN}$ (em caso negativo), quando retirou as fraldas?

e como fez para retirá-las?

4.3. Amamentação natural:

4.3.1. A criança mamou no peito? ( ) não ( ) sim

ECA, até que idade?

como foi o desmame?

4.3.2. A mãe gostou de amamentar? ( ) não ( ) sim

Por quê?

4.3.3. Durante a amamentação:

A mãe fez uso de álcool? ( ) não ( ) sim ( ) ocasional

A mãe fez uso de funo? ( ) não ( ) sim Quantos cigarros por dia?

4.4. Amamentação artificial:

4.4.1. A criança tomou mamadeira?

ECA, quando iniciou?

quando terminou? anos meses.

4.4.2. Características da mamadeira:

Qual a marca da mamadeira?

Qual o tipo de bico da mamadeira: ( ) comum ( ) ortodôntico

A mãe mexeu no furo da mamadeira? ( ) não ( ) sim

ECA, como fez a mudança?

A saída de líquido pelo furo é: ( ) em gotas

( ) em jato contínuo

4.4.3. Qual a postura do bebê ao ser amamentado? (anotar a postura predominante).

( ) deitado

( ) no colo: ( ) vertical ( ) inclinado ( ) horizontal

( ) sentado

( ) em pé

4.4.4. A mãe participa da amamentação? ( ) não ( ) sim ECA, em que postura? (anotar a postura predominante). ( ) em pé

$$
\text { ( ) sentada }
$$

4.5. Dieta de sal:

4.5.1. Com que idade foi introduzida a:

sopa fina: anos

sopa grossa: anos meses

alimentação igual no adulto: meses

4.5.2. A criança aceitou comida salgada? ( ) não( ) sim O que foi feito para a criança aceitar?

4.5.3. A criança não aceita algum alimento? ( ) não ( ) sim ECA, qual(is) :

4.5.4. A criança mastiga alimento(s) duro(s) ( ) não( ) sim ECA, qual(is) :

\subsection{Motricidade:}

4.6.1. Com que idade a criança: 
Rolou:

Firmou a cabeça:

Sentou com apoio:

Sentou sem apoio:

Engatinhou:

Andou com apoio:

Andou sem apoio:

_ $\begin{gathered}\text { meses } \\ \text { anos___ meses } \\ \text { anos_anos_anos_meses }\end{gathered}$

Observações (deverão ser anotadas todas as observações descritas pela mãe pertinentes ao desenvolvimento motor da criança) :

4.7. Linguagem:

4.7.1. Com que idade a criança começou a falar? anos meses

4.7.2. O que é falar para a sra. (o sr.)?

4.7.3. A sra. (o sr.) conversa com a criança? ( ) não ( ) sim Como? (descrever as situações de comunicação)

4.7.4. A fala da criança é entendida por:

( ) mãe ( ) pai ( ) outros ( ) NS/NQR

A fala da criança é parcialmente entendida por: ( ) mãe ( ) pai ( ) outros ( ) NS/NQR

A fala da criança não é entendida por:

( ) mãe ( ) pai ( ) outros ( ) NS/NQR

4.7.5. A criança fala em ritmo: ( ) normal

( ) aumentado

( ) lento

4.8. Hábitos orais:

4.8.1. A criança: usa chupeta? ( ) não ( ) sim

chupa dedo? ( ) não ( ) sim

rói unha? ( ) não ( ) sim

morde objetos? ( ) não ( ) sim

suga objetos? ( ) não ( ) sim

4.9. Percepção visual e auditiva;

4.9.1. A sta. (o sr.) acha que seu filho tem algum problema visual? ( ) não ( ) sim ECA, descreva o problema:

4.9.2. A sra. (o sr.) acha que seu filho tem algum problema auditivo? ( ) não ( ) sim ECA, descreva o problema:

5. Sociabilidade:

5.1. Como o seu filho se relaciona com pessoas da família?

5.2. Como o seu filho se relaciona com outras pessoas?

5.3. A criança já esteve separada dos pais? ( ) não ( ) sim

ECA, qual o motivo?

quanto tempo ficou separado?

onde ficou nesse tempo?

quem tomou conta da criança?

6. Doenças:

6.1. A criança tem alguma doença hereditária?( ) não ( ) sim, qual:

6.2. A criança já teve: 


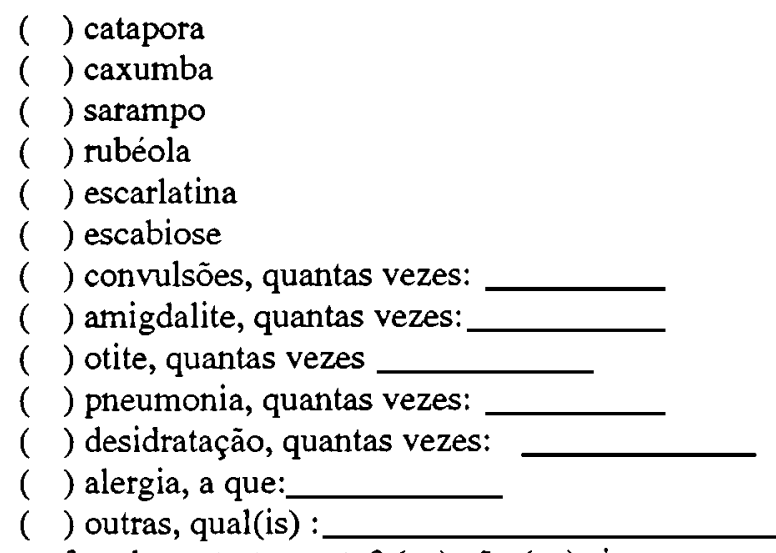

7. A criança fez algum tratamento? ( ) não( ) sim ECA, qual(is) : Para que? quando:

A criança já esteve internada? ( ) não ( ) sim

ECA, qual o motivo:

local:

período de internação:

8. Vacinação:

8.1. As vacinações estão em dia (segundo a carteira de vacinação da criança) ?

( ) não ( ) $\operatorname{sim}($ ) o entrevistador não teve acesso

8.2. As vacinações da criança estão em dia segundo o informante:

9. Medicaçōes:
( ) não( ) $\operatorname{sim}($ ) NS/NQR

9.1. A criança faz uso de remédios? ( ) não ( ) sim ECA, qual(is) : Para que?

9.2. A criança já fez uso de remédios? ( ) não ( ) sim $\mathrm{ECA}$, qual(is) : Para que?

\section{Antecedentes Familiares}

1. Saúde da família:

1.1. Na familia da criança há casos de:

( ) deficiência auditiva

( ) deficiência mental

( ) sindromes

( ) fissura labial e/ou palatal

( ) gagueira

( ) alterações de fala

( ) dificuldades de leitura e/ou escrita

\section{Comportamento da Criança}

1. Como é o dia a dia da criança?

\section{Questionário aplicado às educadoras}

Foi aplicado o mesmo questionário acima dos itens II.4 a IV. 